\title{
Analysis on the Causes of Pragmatic Failure in English Writing and Cultivation of Pragmatic Consciousness
}

\author{
Rao Yufang \\ Wuhan University of Technology \\ Wuhan 430070 China
}

\begin{abstract}
In order to promote the integration with the international community, it is very important to improve students' English ability, especially their writing ability. Therefore, all schools have carried out the reform of English writing teaching. They began to analyze the mechanism of wrong usage in English writing. This will help the school better cultivate students ' pragmatic awareness of English writing and help them reduce pragmatic mistakes in English writing. It also helps to fully mobilize students' positive initiative, improve students' interest in English learning, exercise students' English thinking mode, and improve students' English writing ability. In this paper, we mainly analyze the causes of students' pragmatic failure in English writing teaching. We also discuss the effective ways to improve students' pragmatic consciousness of English writing and put forward the corresponding opinions and Suggestions. We should give full play to the guiding role of teachers, encourage students to read more and understand western culture, and apply network technology and new education mode. So we can help English writing teaching achieve substantial results and progress.
\end{abstract}

Keywords-English writing; Pragmatic failure; Genesis; Pragmatic consciousness

\section{INTRODUCTION}

At present, the teaching and learning of English has received wide attention. Reform is also being carried out in the field of English teaching in China, but the English writing ability of domestic students is still generally poor. In school teaching, due to the defects in teaching methods, students' foundation is not good, their mastery of vocabulary and grammar is poor, and it is difficult for them to conduct simple communication. In addition, in the current English teaching, most teaching systems use written test as the assessment method. They do not pay attention to the training of students' comprehensive application ability. As a result, it is difficult for students to improve their writing and expression skills, and their linguistic knowledge is not guaranteed for the appropriateness and appropriateness of the applied language. Pragmatic knowledge is usually ignored [1]. These problems limit the effect of students' English teaching and are not conducive to students' English learning ability. In order to improve this disadvantage, we need to explore new teaching methods to improve students' writing ability. At present, education institutions have started to study the causes of pragmatic failure in English writing and the methods of cultivating pragmatic consciousness [2].

\section{ANALYSIS ON THE CAUSES OF PRAGMATIC FAILURE IN ENGLISH WRITING}

English writing ability is an important basis for judging students' comprehensive level and ability. However, many students are weak in English writing [3]. According to the statistics of college students' English test results of cet- 4 and cet- 6 and cet- 4 and cet-8, we can see that the majority of Chinese students have relatively poor English writing ability. Most students lost scores in the writing question. What's more, there are various forms of errors, including some spelling mistakes. In order to further improve students' English writing ability and reduce their pragmatic failure in writing, it is urgent for English teachers to analyze the causes of students' mistakes and solve problems.

\section{A. The student's ability to understand language correctly is poor}

When learning a second language, learners often fail to understand the expressions and habits of native speakers. They can't understand the meaning of the second language correctly, so there is the phenomenon of misunderstanding deviation. In the process of writing, most students integrate their native language forms into English writing. They will write in the usual way, which leads to pragmatic failure in writing. In English writing, there are two kinds of pragmatic mistakes in writing [4], the linguistic level and the non-linguistic level. At the language level, the content of errors mainly includes grammar, logical expression, etc. At the non-linguistic level, their problem is the main theme of their article is euphemistic and implicit, with rich and colorful forms, but empty content. In English writing, there are often Shouting slogans, saying empty words, abusing proverbs and allusions. To a certain extent, this greatly reduces the validity and authenticity of the English composition. This will help students develop a formalism that is not conducive to English learning in the future. 
B. The difference between Chinese and western culture is the most important factor that affects Chinese students'

English learning

According to American linguist Robert Kaplan, [5], cultural differences between China and the west have led to serious differences in thinking styles between China and the west. In western countries, people's behavior is relatively straightforward and belongs to "linear". In China, influenced by Confucianism, Chinese people pay attention to the "doctrine of the mean", which belongs to the spiral. Therefore, in the form of articles, Chinese students tend to dislike direct expression. They prefer indirect narratives. Moreover, in western culture, more attention is paid to the realization of selfvalue. In Chinese culture, most people should "give up the little self and make a big difference". People in western countries believe that only the things they have experienced can be more authentic, authentic and persuasive. And in the article of our country student, often will cite many classic examples to prove own viewpoint. It is very prone to pragmatic failures in English writing, writing content and theme, ambiguous, mark, compose more. And it also makes native English-speaking readers think lack certain logic, point of view is not clear.

\section{The traditional education model causes students to lose interest in English writing}

The traditional education model causes students to lose interest in English writing, leading to a large number of pragmatic failures in English writing. At present, most schools English teaching model monotonous, lack of innovation. Influenced by the traditional education model, education model in many classrooms in China is old and monotonous, and most of them adopt traditional teaching methods. The teacher asked questions and the students answered. In addition, some teachers fail to make good use of the example teaching method. In order to enable students to master and understand more writing skills and writing styles, many teachers require students to read and consult relevant materials in their spare time. This takes up students' spare time. Because most students are rebellious, forcing them to study is often counterproductive. This leads to students' resistance and antipathy, which is not conducive to students' future English writing.

\section{In the learning process, students fail to correctly recognize} the connection between words, grammar, structure, etc.

As is known to all, the main purpose of English writing is to conduct interpersonal communication and practical application. Many students will have a large number of words, which is indisputable, because sentences are made up of many words. However, after mastering a certain number of words, students cannot properly and correctly use the words they have learned and do not have a good command of writing skills in the actual writing process. In terms of language expression, it is customary to equate the way of semantic expression in Chinese with the way of English expression, blindly apply it, and make mistakes in cross-cultural pragmatic use. The existence of this phenomenon is that the English education in the process, many teachers and students only pay attention to theory of writing and writing skills and ignore the chapter layout and characteristics of the culture, the traditional English writing teaching methods will affect the students' pragmatic awareness, to influence the formation and development of students' pragmatic competence. Therefore, the teaching of English writing needs to pay attention to the textual differences and pragmatic failures caused by cultural differences.

\section{E. Students have a poor foundation and do not master vocabulary, grammar and coherent words}

The vocabulary errors in student exercises are mainly misused words and mismatched words, and some articles are misused. For example, "look forward to" is also a kind of fixed collocation in English expressions. "to" is used as a preposition. Grammatical errors include morphological errors, i.e. morphological errors such as nouns, verbs, adjectives and adverbs. Cohesion of cohesion coherent error, this article alleged errors mainly includes the person accused of using the wrong word, indicates that using the wrong word, mainly reflected in such aspects as reference, ellipsis, substitution errors, logical reasoning is not correct. Substance use including spelling and punctuation errors, it is very simple, low-level errors, such as spelling errors, students often mistakenly Mosaic beneficial will be beneficial, will adopt and adapt often confuse and so on.

\section{OpINIONS AND SUGGESTIONS ON THE CULTIVATION OF PRAGMATIC CONSCIOUSNESS IN ENGLISH WRITING [8]}

\section{A. Give full play to the guiding role of teachers in teaching}

In teaching, the role of teachers is to guide students to form a virtuous way of thinking. Teachers should find the necessary solutions. For example, in the writing teaching of selfintroduction in English, teachers can use students to demonstrate and explain the key content of the writing process in detail. This will enable students to write in their own way. After each student introduced himself, the teacher asked the students to comment on each other. In this way, students can avoid similar mistakes when they find problems in others. At the same time, it can also enhance students' writing and expression ability. In this way, every student can actively and fully participate in class education and learning, so as to guide students to discover and solve problems themselves. Let students become participants in the classroom, not listeners in the past. We can enable students to keep learning new knowledge and improve learning efficiency in the process of participation. Teachers should improve the original way of writing evaluation so that students can fully participate in writing and complete writing training through preparation, preliminary draft, feedback, modification, rewriting and other stages.

\section{B. Pay attention to cultural differences}

The differences of Chinese and western culture have the very big [9], in laws, customs, culture, there are many different aspects such as social fashion. Therefore, in the process of writing and the difference between these factors must be considered. Before writing, students can first understand the cultural background of western countries and be familiar with the status of the theme in western countries and people's opinions. In this way, students can analyze problems and 
expound views from the perspective of western countries. Students should summarize and analyze constantly. When students encounter relatively obvious differences of opinion, they should summarize these views and prevent them from making the same mistakes in the future. In this way, students can understand the reasons for their pragmatic mistakes in writing. In addition, students can do a lot of English reading. Books are able to help people to understand the background at that time all things one of the effective tools, not only can help students understand western culture and customs, be familiar with the western history, will also be able to grasp the characteristics of English writing and grammar, you can put this to use, good ideas and sentences grammar reference to his article. In this way, we can make sure the theme of the article is prominent. We can use a variety of skills, such as cohesion and transition, to make the article natural and coherent.

\section{Understand the purpose of writing correctly}

The purpose of English writing is not only to express your views correctly, but also to express them fluently and concisely. In the process of English writing, more attention is paid to the combination of reality, less exaggeration and embellishment, and the content of discourse is presented in a way that is understandable and acceptable to the audience. In the process of English writing, we often see professional terms and archaic words, abbreviations and colloquial words, which are an important reflection of English professionalism. In English writing, the most important thing is to conform to the original intention and not need to be beautified and embellished like film titles or other literary works. But we should try to highlight as much as possible the specific role of the subject of the description or the viewpoint. Therefore, the purpose of our writing should be more practical than literary creation. On the basis of SKOPOS theory, English writing should constantly pursue precision, simplicity and efficiency to better convey the author's intention and views [10,11]. We should pay attention to the grasp of key points, reduce semantic redundancy and misuse of words, and make sentences short and concise, so as to ensure the accuracy of English writing to the maximum extent.

\section{Establish a complete and practical curriculum system and actively introduce network technology}

We should establish an interactive platform with other schools to promote exchanges among schools. We should keep abreast of the development and development of English writing in schools. In this way, we can make up for our shortcomings. We can also observe other schools, teaching models and practical applications through live broadcast. In this way, students' interest in learning can be improved to a certain extent and their specific writing ability in English writing can be improved. At the same time, we can establish a reasonable English writing teaching method and system. The emphasis of English writing is practical ability. The specific event operation course is an education method to seek and master scientific knowledge through practical operation. We should establish a perfect education system and system and combine the new education model. In the writing process, teachers should make targeted comments on each link. Teachers can creatively adopt the mutual assessment mechanism to allow students to evaluate each other. In this way, students can supervise and promote each other and improve together. Teachers can see the shortcomings between students from the perspective of partners. So as to improve the effectiveness and value of English writing teaching.

\section{E. Cooperative teaching mode is adopted in the writing class to stimulate students' interest in writing}

In the process of cooperative learning, teachers should create opportunities for students to participate in classroom activities. Teachers should let students learn to express their thoughts and share their feelings with other students in the learning process. Students learn from each other and make progress together by listening to others' summaries. Through the cooperative learning model, we can make the interactive effect of classroom more obvious. This improves the communication between students and makes the classroom atmosphere more relaxed and pleasant. Through the learning model of mutual help, we can enable students with relatively weak learning ability to keep learning and making progress. Cooperative learning mode can improve students' English thinking and improve their learning efficiency. Teachers can design a knowledge - related English environment for students to discuss solutions. Through this process, students can not only learn English knowledge and improve their ability to solve problems, but also strengthen their spirit of solidarity and cooperation.

\section{CONCLUSION}

The main reason for pragmatic failure in English writing is the difference between Chinese and western cultures. The main purpose of English writing is to strengthen the communication and connection between people, express their own views, and communicate ideas and ideas with each other. However, as a non-native English language, Chinese students are more or less mixed with Chinese expressions in English writing. This is inevitable, and it is the stage that every English learner must go through. This paper analyzes the English writing teaching process, students writing causes of pragmatic failures, and continues to improve students' English writing of pragmatic awareness training, some effective measures to put forward the corresponding opinions and Suggestions. This paper tries to help English writing teaching achieve substantial results and progress. However, in order to minimize the impact of Chinese on our English writing, we must fully understand the cultural differences between China and the west and try our best to understand the western history and culture. At the same time, we need to use a variety of learning methods for enrichment, consciously cultivate English writing ability, make one can more accurately and more fully to express self through the article.

\section{REFERENCES}

[1] English group, foreign language teaching steering committee of higher education. English teaching syllabus for English majors in higher education. Shanghai foreign language education press, 2000.

[2] Cai Chuiyun. On the cultivation of students' pragmatic knowledge from pragmatic failure [J]. Higher education BBS, 2003, (2). 
[3] Wang Yi et al. Investigation and analysis on the current situation of English writing teaching in university of science and engineering [J]. Foreign language,2006(5).

[4] Guo Liqiu, Wang Hongli. An analysis on the types and causes of errors in English writing of Chinese students [J]. Sino-us English Teaching, 2004, (5).

[5] Kaplan, Robert. B. "Cultural Thought Patterns", inter-cultural Education Language Learning [J],1996, 16(1-2).

[6] Pu Jianzhong. Class connection, collocation and word block in English vocabulary teaching [J]. Journal of PLA foreign language institute, 2003,6.

[7] Luo Lisheng. A study on the analysis of errors in English naming in learners' transitional language [J]. Xi 'an: fore ign language teaching, vol. 18, 2007, no. 1, p56-59.
[8] Dai Weidong, Shu Dingfang. Some problems in comparative analysis, error analysis and interlingual studies [J]. Foreign languages (journal of Shanghai foreign studies university), no. 5,1994.

[9] Guo Chunjie. The relationship between native language thinking and foreign language writing ability: a study on the composition process of high school students' English picture reading [J]. Guangzhou: the fourth issue of modern foreign language,1998.

[10] Yuan Fang. An empirical study on the analysis of errors in English writing of Chinese college students [J]. Journal of Gansu united university (social science edition),2007(1).

[11] Zhang Juwen. The essence and function of pragmatic consciousness from a philosophical perspective [J]. Journal of Zhengzhou institute of aeronautical industry management, 2003, (12). 